\title{
Analysis of the contents of consultations requested by the emergency department
}

\author{
Mustafa Boğan ${ }^{1}$, Hasan Sultanoğlu ${ }^{1}$, Mehmet Cihat Demir ${ }^{1}$, Mehmet Karadağ ${ }^{2}$, Hasan Baki Altınsoy ${ }^{3}$ \\ ${ }^{1}$ Emergency Department, School of Medicine, Düzce University, Düzce, Turkey; ${ }^{2}$ Department of \\ Biostatistics, Medicine Faculty, Hatay Mustafa Kemal University, Hatay, Turkey; ${ }^{3}$ Radiology Department, \\ School of Medicine, Düzce University, Düzce, Turkey
}

\begin{abstract}
Background and objectives: Every year several thousand patients attend the hospital emergency department (ED). The aim of the present study was to evaluate the content of the consultations requested from the emergency department.
\end{abstract}

Methods: The patients who had presented to the adult emergency department between January 1, 2020 and January 31, 2020, and who had undergone consultation by at least one clinic were included in the study. Age, gender, the number of consultation required at the same admission, the clinic from which the consultation sought, time required to respond to the request and the outcomes of the consultations were analyzed.

Results: The total number of emergency department presentations was 8930 patients and at least one consultation had been requested for $6.64 \%(n=593)$ patients. The mean duration of answering the consultation was $85.76 \pm 90.33$ minutes. Consultations were requested from the cardiology most frequently ( $n=188,19 \%)$, followed by the pulmonology department $(n=181$, 18.3\%). Discharge was recommended with prescription in 235 (39.6\%) consultations. Internal medicine was the clinic, which recommended treatment at the emergency room most frequently ( $n=45,22.4 \%$ ) and the most commonly recommended treatment was erythrocyte suspension replacement $(n=7)$. The clinic that demanded additional tests most commonly was determined to be the pulmonology department $(n=41,22.9 \%)$ and arterial blood gases analysis was the most commonly demanded test $(n=16)$.

Conclusion: In our study, the rate of consultations requested was seen to be lower and the rate of cases that required hospitalization was seen to be higher. The duration of answering consultations was found to be longer than desired and institutional protocols should be developed for shortening this duration.

IMC J Med Sci 2021; 15(1): 004

\section{Background}

Every year, there are millions of admissions in the emergency departments of our country. A multidisciplinary approach is required for the care of some patients. In such a case, consultation is requested from other departments. Although the regulations specify the rules of requesting consultations failures are sometimes experienced
[1]. The problems during the consultation process reduce the patients' satisfaction and also prolong the length of stay in the emergency department [2]. According to our observations, many clinics request additional tests, treatments and consultations from other clinics for patients for whom consultation is requested from the emergency department and requires a re-

*Correspondence: Mustafa Boğan, Emergency Department, Health Research and Application Hospital, Düzce University, Düzce, Turkey, Posta code: 81620. Email: mustafabogan@hotmail.com 
consultation when the test results are completed. The aim of the present study was to evaluate the content of the consultations requested from the emergency department (ED).

\section{Methods}

The ethics committee approval was obtained from Düzce University prior to the study (date: 02.03.2020, decision number: 2020/25). The ED, where the study was conducted, is a part of Düzce University hospital. Therefore, intern, resident, specialist and academic staff of medical school also work at the ED. Between February 1, 2019 and January 31, 2020, a total of 56236 patients were admitted in our ED. During this time, at least one consultation was requested for 8539 (annually $15.18 \%)$ patients.

The patients who had presented to the ED between January 1, 2020 and January 31, 2020, and who had undergone consultation by at least one clinic were included in the study. Age, gender, the number and name of the clinics the consultations was requested from, and the outcomes of the consultations were recorded. The consultations requested from obstetrics clinic for pregnancy follow-up were excluded. The consultations which were not ended by related clinic because of an emergency status (such as emergency operation, percutaneous coronary intervention) were excluded from the study.

\section{Process of the consultation at the ED}

- The patients were examined by an emergency doctor (intern, resident) at first admission.

- The findings and patients were re-evaluated by responsible specialist or assistant professor (doctor).

- If any test (laboratory, radiological, etc) requested, the results were obtained in 1-3 hours.

- After results obtained, if it was needed, a consultation was requested from other clinics.

- A digital consultation form was created at hospital information system and related clinics were alerted by a phone call.
- The respective clinic requested for consultations were required to answer in $\mathbf{3 0}$ minutes according to in hospital procedures.

- The treatment of patients was administered according to result of consultation and decision of responsible physician of ED.

\section{The consultation of the respective clinic was analyzed based on the following criteria:}

- The duration of completing the consultation (the time between creating a digital consultation form and accomplishment of the consultation).

- Recommendation for an additional test at the emergency department.

- Recommendation for an additional treatment at the emergency department.

- Recommendation for an additional consultation from another clinic.

- Recommendation for re-consultation following the demanded procedures.

- Outcome of the patients.

Outcomes were categorized into three groups such as (a) needed hospitalization (hospitalization at the clinic, exitus in ED, recommendation for follow-up at intensive care unit), (b) discharged (discharge after treatment at emergency room, recommendation for outpatient clinic admission after prescription) and (c) others (such as treatment rejection, leave without permission of doctors). The consultations were analyzed for the content detailed above and the obtained data were evaluated.

Statistical method: For the descriptive statistics, the mean \pm standard deviation, median, first quartile (Q1) and the third quartile (Q3), minimum and the maximum values were given for numerical variables, and numbers and percentages were given for the categorical variables. The KruskalWallis test was used for comparison of the durations of the departments from which consultation was requested. Statistical analyses were carried out using the SPSS Windows version 23.0 package program and a $p$ level of $<0.05$ was accepted as statistically significant. 


\section{Results}

The total number of emergency department presentations was 8930 patients and at least one consultation had been requested for $6.64 \%$ ( $n=$ 593) patients. The mean age of these patients was $60.05 \pm 21.37$ years and 328 (55.3\%) were males. A total of 987 consultations were requested for these patients and 389 (65.6\%) patients had been consulted by a single clinic. Most of the patients ( $\mathrm{n}$ $=330,55.6 \%)$ needed hospitalization (Table-1).

Table-1: Descriptive data of the patients

\begin{tabular}{lcc}
\hline Parameters & $\mathbf{n}$ & $\mathbf{\%}$ \\
\hline Gender & 328 & 55.3 \\
Male & 265 & 44.7 \\
Female & $\mathbf{n}$ & $\mathbf{\%}$ \\
Number of consultations at the & & \\
same admission & 389 & 65.6 \\
1 consultation & 95 & 16.0 \\
2 consultation & 61 & 10.3 \\
3 consultation & 30 & 5.1 \\
4 consultation & 10 & 1.7 \\
5 consultation & 4 & 0.7 \\
6 consultation & 0 & 0.0 \\
7 consultation & 1 & 0.2 \\
8 consultation & 3 & 0.5 \\
9 consultation & $\mathbf{n}$ & $\%$ \\
Outcome of the patients & 330 & 55.6 \\
Hospitalized & 235 & 39.6 \\
Discharged & 28 & 4.8 \\
\hline Others & &
\end{tabular}

Consultations were requested most frequently from cardiology department ( $n=188,19 \%$ ), followed by the pulmonology department ( $n=181,18.3 \%$ ). Additional treatment and tests were recommended for 201 (20.4\%) and 179 (18.1\%) cases respectively at the emergency department. A total of 242 (24.5\%) consultations were requested from another department and there were 146 (14.8\%) request/demand for re-consultation by the clinicians following the planned procedure (Table-2). The mean duration of answering the consultation was $85.76 \pm 90.33$ minutes. The department of cardiovascular surgery (CVS) needed the maximum time (581.67 $\mathrm{min}$ ) to answer/respond the consultation request. When the procedures carried out for the patients were analyzed, a total of 3 patients were determined to have been consulted by the CVS clinic, and of these, one had undergone an urgent operation, and another was hospitalized at the $77^{\text {th }}$ min of consultation. Hence, it was found that consultation was completed after the urgent procedures had been accomplished and thereby, the duration of answering the question seemed prolonged (Table-3).

Table-2: Descriptive data of consultations

\begin{tabular}{|c|c|c|}
\hline $\begin{array}{l}\text { The clinic from which } \\
\text { consultation was requested }\end{array}$ & $\mathbf{n}$ & $\%$ \\
\hline Forensic medicine & 3 & 0.3 \\
\hline Cardiovascular surgery & 3 & 0.3 \\
\hline Obstetrics and gynecology & 4 & 0.4 \\
\hline Thoracic surgery & 14 & 1.4 \\
\hline Anesthesia & 16 & 1.6 \\
\hline Urology & 17 & 1.7 \\
\hline Ear-Nose-Throat & 23 & 2.3 \\
\hline Psychiatry & 23 & 2.3 \\
\hline Ophthalmology & 31 & 3.1 \\
\hline Orthopedics & 36 & 3.6 \\
\hline Infectious diseases & 41 & 4.2 \\
\hline Neurosurgery & 43 & 4.4 \\
\hline General surgery & 105 & 10.6 \\
\hline Neurology & 107 & 10.8 \\
\hline Internal medicine & 152 & 15.4 \\
\hline Pulmonology & 181 & 18.3 \\
\hline Cardiology & 188 & 19.0 \\
\hline $\begin{array}{l}\text { Recommended additional } \\
\text { treatment at emergency } \\
\text { room }\end{array}$ & $\mathbf{n}$ & $\%$ \\
\hline Yes & 201 & 20.4 \\
\hline No & 786 & 79.6 \\
\hline $\begin{array}{l}\text { Recommended additional } \\
\text { tests at emergency room }\end{array}$ & $\mathbf{n}$ & $\%$ \\
\hline Yes & 179 & 18.1 \\
\hline No & 808 & 81.9 \\
\hline $\begin{array}{l}\text { Demand for } \\
\text { re-consultation }\end{array}$ & $\mathbf{n}$ & $\%$ \\
\hline Yes & 146 & 14.8 \\
\hline No & 841 & 85.2 \\
\hline $\begin{array}{l}\text { Recommended additional } \\
\text { consultation from the } \\
\text { other clinics }\end{array}$ & $\mathbf{n}$ & $\%$ \\
\hline Yes & 242 & 24.5 \\
\hline No & 745 & 75.5 \\
\hline
\end{tabular}


Table-3: Time required by different clinics to answer the consultation request

\begin{tabular}{lcc}
\hline Clinic from which consultation was requested & Median [Q1 Q3] (min) & Mean time (min) \\
\hline Total & $\mathbf{6 5}[\mathbf{3 6} \mathbf{1 0 6}]$ & $\mathbf{8 5 . 7 6 \pm 9 0 . 3 3}$ \\
Anesthesia & $15.00[8.0075 .50]$ & 68.06 \\
Obstetrics and gynecology & $36.00[35.0043 .00]$ & 38.00 \\
Forensic medicine & $43.00[25.0064 .00]$ & 44.01 \\
Neurosurgery & $43.00[29.0068 .00]$ & 53.58 \\
Ophthalmology & $43.00[12.0090 .00]$ & 77.77 \\
Infectious diseases & $56.00[45.0089 .00]$ & 73.39 \\
Neurology & $58.00[35.0089 .00]$ & 77.30 \\
Ear-nose-throat & $60.00[25.0093 .00]$ & 61.48 \\
Cardiology & $61.00[40.00102 .00]$ & 84.08 \\
Psychiatry & $64.00[39.00110 .00]$ & 71.52 \\
Internal medicine & $67.50[36.00100 .50]$ & 79.66 \\
Orthopedics & $68.50[34.50135 .50]$ & 91.72 \\
General surgery & $69.00[49.00132 .00]$ & 94.81 \\
Pulmonology & $75.00[50.00108 .00]$ & 88.71 \\
Urology & $113.00[56.00221 .00]$ & 167.13 \\
Thoracic surgery & $114.00[33.00223 .00]$ & 176.08 \\
Cardiovascular surgery & $585.00[160.001000 .00]$ & 581.67 \\
\hline Kruskall Walis & & \\
\hline
\end{tabular}

Kruskall Wallis $H=59.42, p=0.001, Q$ : Quartile, M: median, sd: standard deviation

Table-4: Contents of the consultations answered by the clinics

\begin{tabular}{lcccc}
\hline $\begin{array}{l}\text { The clinic from which } \\
\text { the consultation was } \\
\text { requested }\end{array}$ & $\begin{array}{c}\text { Additional treatment } \\
\text { at emergency room } \\
\mathbf{n = 2 0 1 ( \% 1 0 0 )}\end{array}$ & $\begin{array}{c}\text { Additional tests at } \\
\text { emergency room } \\
\mathbf{n = 1 7 9 ( \% 1 0 0 )}\end{array}$ & $\begin{array}{c}\text { Re-consultation } \\
\mathbf{n = 1 4 6 ( \% 1 0 0 )}\end{array}$ & $\begin{array}{c}\text { Additional } \\
\text { consultation } \\
\mathbf{n}=\mathbf{2 4 2}(\% \mathbf{1 0 0})\end{array}$ \\
\hline Anesthesia & - & - & - & - \\
Obstetrics and & - & - & $1(0.7 \%)$ & $1(0.4 \%)$ \\
Gynecology & - & - & - & - \\
Forensic medicine & $10(5 \%)$ & $11(6.1 \%)$ & $8(5.5 \%)$ & $9(3.7 \%)$ \\
Neurosurgery & $8(4 \%)$ & - & $1(0.7 \%)$ & $4(1.7 \%)$ \\
Ophthalmology & $17(8.5 \%)$ & $17(9.5 \%)$ & $12(8.2 \%)$ & $13(5.4 \%)$ \\
Infectious diseases & $37(18.4 \%)$ & - & $26(17.8 \%)$ & $43(17.8 \%)$ \\
Neurology & $4(2 \%)$ & - & - & $4(1.7 \%)$ \\
Ear-nose-throat & $24(11.9 \%)$ & $25(14.0 \%)$ & $10(6.8 \%)$ & $19(7.9 \%)$ \\
Cardiology & $3(1.5 \%)$ & $1(0.6 \%)$ & - & - \\
Psychiatry & $45(22.4 \%)$ & $32(17.9 \%)$ & $28(19.2 \%)$ & $54(22.3 \%)$ \\
Internal medicine & $5(2.5 \%)$ & $4(2.2 \%)$ & $5(3.4 \%)$ & $6(2.5 \%)$ \\
Orthopedics & $9(4.5 \%)$ & $18(10.1 \%)$ & $22(15.1 \%)$ & $28(11.6 \%)$ \\
General surgery & $30(14.9 \%)$ & $41(22.9 \%)$ & $30(20.5 \%)$ & $51(21.1 \%)$ \\
Pulmonology & $6(3 \%)$ & $1(0.6 \%)$ & $2(1.4 \%)$ & $4(1.7 \%)$ \\
Urology & $2(1 \%)$ & $1(0.6 \%)$ & $1(0.7 \%)$ & $5(2.1 \%)$ \\
Thoracic surgery & $1(0.5 \%)$ & - & - & $1(0.4 \%)$ \\
Cardiovascular surgery & & & & \\
\hline
\end{tabular}


Internal medicine was the clinic, which recommended additional treatment at the emergency room most frequently ( $n=45,22.4 \%$ ) and the most commonly recommended treatment was erythrocyte suspension replacement $(n=7)$. The clinic that demanded additional tests most commonly was the Pulmonology department $(n=$ $41,22.9 \%$ ) and arterial blood gases analysis was the most commonly demanded test $(n=16)$. Internal medicine was found to recommend highest additional consultation from another clinic ( $n=54,22.3 \%)$ and pulmonology was the clinic that was most commonly recommended $(n=14)$. Pulmonology was the clinic that demanded re-consultation most frequently ( $n=30,20.5 \%$ ). Table-4 shows the details of the contents of the consultations by different departments.

\section{Discussion}

Some of the patients who present to the emergency department may need to be evaluated by different clinics. In such situations, the process of the consultations has an important role in the operation of the emergency room. In the onemonth analysis in our study, $6.64 \%$ of the patients were seen to have undergone consultation by at least one clinic. This rate reaches $10.89 \%$ when pregnant women undergoing consultation by the obstetrics clinic are also included (also annually $15.18 \%)$. Dönmez et al. determined that $21.6 \%$ of the patients presenting to the emergency room had undergone consultation by other clinics [3]. In the analysis of emergency room presentations during 2 months by Aygencel et al., 30\% of the patients were determined to have undergone consultations by at least one clinic [4]. In a review by Lee et al., the rate of consultations from the emergency room to the other clinics was $20-40 \%$ [5]. In our study, the rate of consultations was lower because our center is located in a small city that has approximately 300,000 populations and there are three hospitals (this center, a state hospital, and a special hospital) around. Our center is tertiary educational hospital and all patients were discussed by ED doctors that included emergency resident, emergency specialist and lecturers before consultations. This might have contributed to reduce the rate of consultations. However, this might be associated with legal risks.

In our study, $65.6 \%$ of the patients had undergone one consultation by other clinic. Consultations were found to be most commonly requested from the cardiology (19\%) and the pulmonology (18.3\%). Similar to our findings, Dönmez et al. also found that consultation from ED were most frequently requested from cardiology and pulmonology departments [3]. Demircan et al. found that consultations were most often requested from the internal medicine (32\%) and cardiology (26\%) clinics [6]. In another study from our country, emergency consultations had been requested from the internal medicine clinic most frequently [2]. Based on the current data, we may conclude that most of the problems could be solved with a single consultation and that consultations had been requested from the internal medicine disciplines most commonly. Our center has specialized units such as angiography, interventional radiology, oncology, pediatric surgery and trauma, and dialysis units. The single angiography unit of the city is located in our center. Because of these specialized facilities all patients who require special procedures are transferred here. The city has high rate air pollution during autumn and winter because of wide industrial area and geographical condition of the city. There are many patients that suffer from chronic obstructive pulmonary disease in the city and one of the most common reasons to visit ED is dyspnea. For these reasons, cardiology and pulmonology departments had high rate of consultations.

In the present study, the mean duration of answering consultations was $85.7 \pm 90.3$ minutes. The longest duration belonged to the CVS clinic (581.67 $\mathrm{min}$ ); however, when the files of the patients consulted by the CVS clinic were analyzed, the patients who had undergone consultation whose final reports had not been written for a long time were determined to have undergone urgent operations or transferred to the intensive care unit hours before. The clinics from which the consultations had been requested most by the emergency department were seen to have an answering time longer than the mean; this duration was $84.08 \mathrm{~min}$ for the cardiology and $88.71 \mathrm{~min}$ for 
the pulmonology clinics. Karakaya et al. reported the mean duration of answering consultations as $22.33 \pm 25.04 \mathrm{~min}$ [2]. Dönmez et al. reported the nephrology clinic required the longest time (mean $306 \pm 393 \mathrm{~min}$ ) to respond to request for consultation while it was $212 \pm 182 \mathrm{~min}$ for the pulmonology clinic and $186 \pm 152 \mathrm{~min}$ for the cardiology clinic [3]. A prolonged time of answering consultations means prolonged stay in emergency room and thereby increased mortality and morbidity $[7,8]$. In our country, the legal time for answering emergency room consultations has been specified as 30 minutes [1]. We consider that the reasons for the long consultation time are the additional tests, the hierarchical patient counseling habit and requesting more than one consultation during the same period, particularly at busy hours. Physical conditions of the hospital building can have effect on the consultation time. Other departments are located far away from the ED in our center (approximately 20 minutes by walking). We think the hierarchical patient counseling habit and long distance to ED are some of causes of long consultation time. This may be solved by some innovative approach such as telemedicine and use of small vehicles to travel the distance fast.

In our study, $14.8 \%$ to $24.5 \%$ cases required reconsultation, additional treatment/tests or consultations from other clinics. In the study of Karakaya et al., additional tests were demanded as in our study [2]. However, another study reported additional tests were required for half of their study patients and treatment recommendations were given to one third cases at the emergency room [4]. Although it may be suggested to plan the tests before requesting a consultation, many tests cannot be requested at the emergency rooms due to the health policies. When looked into the raw data, we found that $23.9 \%$ of the patients who were hospitalized were requested additional processing. Additional processing can cause long length of stay in ED.

In our study, we found that $55.6 \%$ cases required hospitalization. Almost similar rate (49\%) of hospitalization was reported by others $[4,6]$. This comparatively higher rate of hospitalization in our center could be due to the fact that many patients with serious ailments prefer to come to our center as ours is a tertiary care hospital that perform many specialized procedures. The rate of consultations requested was seen to be lower and the rate of cases that required hospitalization was seen to be higher in our study. The duration of answering consultations was seen to be longer than desired. The hierarchical patient counseling habit, long distance of ED from other clinics, and being a tertiary hospital are the reasons of this condition. These problems could be solved by telemedicine and right hospital consultation policy.

Declaration of conflicting interests: The authors declared no potential conflicts of interest with respect to the research, authorship, and/or publication of this article.

Funding: The authors received no financial support for the research, authorship, and/or publication of this article.

Ethical approval: Ethics committee approval was obtained from Düzce University.

Human rights: Authors declare that human rights were respected according to the Declaration of Helsinki.

\section{References}

1. Republic Of Turkey Ministry Of Health, General Directorate of Health Services. Yatakli Sağlik Tesislerinde Acil Servis Hizmetlerininuygulama Usul Ve Esaslari Hakkinda Tebliğdedeğişiklik Yapilmasina Dair Tebliğ. Resmi Gazete. 2018; 30338

2. Karakaya Z, Gökel Y, Açıkalın A, Karakaya O. Evaluation of the process and effectiveness of consultation system in the Department of Emergency Medicine. Turkish Journal of Trauma \& Emergency Surgery. 2009; 15(3), 210-216.

3. Dönmez SS, Durak VA, Torun G, Köksal Ö, AYDIN Ş. Analysis of the process of consultations in the Emergency Department. Uludağ Üniversitesi Tıp Fakültesi Dergisi. 2017; 43(1): 23-28. 
4. Aygencel G, Ahmet NAS, Saritaş H, Deryal K, Demircan A. General characteristics of internal medicine consultations in the emergency service of a University Hospital. Firat Tıp Dergisi. 2012; 17(4): 219-222.

5. Lee RS, Woods R, Bullard M, Holroyd BR, Rowe $\mathrm{BH}$. Consultations in the emergency department: a systematic review of the literature. Emerg Med J. 2008; 25(1): 4-9.

6. Demircan C, Çekiç C, Akgül N, Odabaşi A, Çalişir $\mathrm{N}$, Kiyici $\mathrm{S}$, et al. Profiles of the patients in the
Emergency Internal Medicine Unit: One-year experience. Uludağ Üniversitesi Tıp Fakültesi Dergisi. 2005; 31(1): 39-43.

7. Willoughby KA, Chan BT, Strenger M. Achieving wait time reduction in the emergency department. Leadership in Health Services. 2010; 23(4): 304-319.

8. Shen $Y$, Lee LH. Improving the wait time to consultation at the emergency department. BMJ Open Quality. 2018; 7(1): e000131. 